\title{
Effects of Overexpression of WRI1 and Hemoglobin Genes on the Seed Oil Content of Lepidium campestre
}

\author{
Emelie Ivarson ${ }^{*}$, Nélida Leiva-Eriksson ${ }^{2}$, Annelie Ahlman ${ }^{1}$, Selvaraju Kanagarajan ${ }^{1}$, \\ Leif Bülow ${ }^{2}$ and Li-Hua Zhu ${ }^{1 *}$ \\ ${ }^{1}$ Department of Plant Breeding, Swedish University of Agricultural Sciences, Alnarp, Sweden, ${ }^{2}$ Department of Pure and \\ Applied Biochemistry, Lund University, Lund, Sweden
}

\section{OPEN ACCESS}

Edited by:

Soren K. Rasmussen,

University of Copenhagen, Denmark

Reviewed by:

Randall J. Weselake,

University of Alberta, Canada

Nacer Bellaloui,

United States Department

of Agriculture - Agricultural Research

Service, USA

*Correspondence: Li-Hua Zhu

Li-Hua.Zhu@slu.se

Emelie Ivarson

emelie.ivarson@s/u.se

Specialty section:

This article was submitted to

Plant Biotechnology,

a section of the journal

Frontiers in Plant Science

Received: 17 August 2016 Accepted: 19 December 2016

Published: 09 January 2017

Citation

Ivarson E, Leiva-Eriksson N,

Ahlman A, Kanagarajan S, Bülow L

and Zhu L-H (2017) Effects

of Overexpression of WRI1

and Hemoglobin Genes on the Seed

Oil Content of Lepidium campestre.

Front. Plant Sci. 7:2032.

doi: 10.3389/fpls.2016.02032
The wild species field cress (Lepidium campestre), belonging to the Brassicaceae family, has potential to be developed into a novel oilseed- and catch crop, however, the species needs to be further improved regarding some important agronomic traits. One of them is its low oil content which needs to be increased. As far as we know there is no study aiming at increasing the oil content that has been reported in this species. In order to investigate the possibility to increase the seed oil content in field cress, we have tried to introduce the Arabidopsis WRINKLED1 (AtWR/1) or hemoglobin (Hb) genes from either Arabidopsis thaliana (AtHb2) or Beta vulgaris (BvHb2) into field cress with the seed specific expression. The hypothesis was that the oil content would be increased by overexpressing these target genes. The results showed that the oil content was indeed increased by up to 29.9, 20.2, and $25.9 \%$ in the transgenic lines expressing AtWR/1, AtHb2, and BvHb2, respectively. The seed oil composition of the transgenic lines did not significantly deviate from the seed oil composition of the wild type plants. Our results indicate that genetic modification can be used in this wild species for its fast domestication into a future economically viable oilseed and catch crop.

Keywords: Lepidium campestre, metabolic engineering, hemoglobin, WRINKLED1, oil content

\section{INTRODUCTION}

A growing world population, changing climate, and depletion of fossil oils in a near future require sustainable oil sources for a bioeconomy-based society. Plant oil has become one of the very attractive alternatives to fossil oil in the recent years as it is renewable and can be easily tailormade for end uses using gene technology. Plant oil is widely used as food oil, in the food or chemical industries and as biodiesels. Today, a few oil crops constitute the greatest part of the world plant oil production, and the possibility to increase the oil content of these crops is limited due to various reasons. Rapeseed and oil palm already have high oil content, and the potential for further increasing the seed oil content is rather limited. An increase in the oil content of soybean would be on the expense of the protein content and is thus not alternative since protein is the most desirable component of the soybean seeds (Carlsson et al., 2011). Developing or domestication of new and high-yielding oil species with oil compositions tailored for end users would be a better choice in this context.

Field cress (Lepidium campestre) is a wild species with promising agronomic traits, and thus has a potential to become a future new oilseed crop. It belongs to the Brassicaceae family and is distributed all over the world (Al-Shehbaz, 1986). It has shown a highyield potential (5 ton/ha) under field conditions with extensive weed control, and it is 
also winter hardy (Nilsson et al., 1998). Being a biennial species, it has the potential to function as a catch crop for reduced tillage and nutrient leaching (Merker et al., 2010). One of the major problems with field cress is the low oil content, which is around $20 \%$. Moreover, the oil composition was not favorable as food oil. Therefore, both the oil content and composition need to be improved. Increasing the oil content by intra-specific crossing is inefficient as the genetic variation in oil content is low within the L. campestre species according to our preliminary studies. Genetic engineering would be a better alternative to modify the oil content and composition. Since this is still a wild species, no studies on oil content have been reported in the species so far. However, in our previous study in this species, the oil composition was altered by downregulation of two key enzymes. The oxidative and temperature stable oleic acid was increased from around $10 \%$ in the wild type (WT) to over $80 \%$ in the transgenic lines. Furthermore, the level of erucic acid was decreased from over $20 \%$ down to $0.2 \%$ (Ivarson et al., 2016).

The seed oil, mainly in the form of triacylglycerol (TAG), is largely synthesized through the Kennedy pathway where several key enzymes have been identified (Kennedy, 1961). Upregulation of these enzymes could result in alteration of seed oil content. It has been reported that both overexpression of the enzyme glycerol-3-phosphate acyltransferase (GPAT) and diacylglycerol acyltransferase (DGAT) could increase the oil content in Arabidopsis (Jain et al., 2000; Jako et al., 2001). However, a more efficient way is to modify expression of transcription factors that are involved in the oil biosynthesis. The most successful example in this regard is the transcription factor WRINKLED1 (WRI1) (Focks and Benning, 1998; Cernac and Benning, 2004), in which a wril knock out mutation resulted in a seed oil content reduction of $80 \%$. An overexpression of a WRI1-like gene from Brassica napus in Arabidopsis yielded an increase in seed oil content of 10-40\% in the transgenic lines (Liu et al., 2010). Overexpression of maize WRI1 in maize resulted in transgenic lines with up to $46 \%$ increase in oil content (Shen et al., 2010). By simultaneously overexpressing WRI1 and DGAT1 and suppress the triacylglycerol lipase SUGARDEPENDENT1 (SDP1) in Arabidopsis, an increase in both seed oil content and seed mass was achieved. Individual manipulations of the three genes resulted in lower increases in seed oil content and seed mass, thus an additive effect of the multigene engineering was speculated (van Erp et al., 2014). The transcription factors B. napus LEAFY COTYLEDON1 (BnLEC1) and LEC1-LIKE $(B n L 1 L)$ were conditionally expressed in canola, resulting in oil content increases of $2-20 \%$ without any negative influence on major agronomic traits (Tan et al., 2011).

Plant hemoglobin genes have also been proved to increase the seed oil content (Vigeolas et al., 2011). There are in principal two types of plant hemoglobins, i.e., symbiotic and nonsymbiotic hemoglobins (nsHbs). The symbiotic hemoglobins (leghemoglobins) are mainly found in the root nodules of legumes that are infected by symbiotic nitrogen-fixing bacteria, and are believed to facilitate oxygen transport to the bacteria (Trevaskis et al., 1997) and at the same time buffer the level of free oxygen available in order to avoid inactivation of the oxygen-sensitive bacterial nitrogenase enzyme (Appleby et al., 1988). The nsHbs are known to be involved in nitric oxide (NO) metabolism, and possibly serve a role in signal transduction pathways of plant hormones (Hill, 2012). nsHbs are divided into mainly two classes; class 1 (nsHb1) and class 2 (nsHb2), based on phylogenetic characteristics, patterns of gene expression and their oxygen-binding capacities (Vigeolas et al., 2011). The expression of class-1 nsHb1 genes has usually been reported in organs different from those related to reproduction or reproductive stages (Nie and Hill, 1997; Trevaskis et al., 1997; Parent et al., 2008). In Arabidopsis and sugar beet, for instance, class- 1 nsHb1 have been shown to be expressed in seeds, germinating seedlings, hypocotyls and roots (Trevaskis et al., 1997; Leiva-Eriksson et al., 2014). Differently, class- 2 nsHbs genes have often been detected in reproductive organs or in processes related to such as embryogenesis and seed maturation. Thus, class- 2 nsHbs have been found to be expressed in flowers of Arabidopsis and sugar beet (Trevaskis et al., 1997; Leiva-Eriksson et al., 2014).

Class 1-nsHbs have a high affinity for oxygen, while class 2-nsHbs show a much lower oxygen affinity. The functions of $A t H b 2$ is not as established as is for $A t H b 1$, and due to their different characteristics their functions likely differ, but might also overlap (Spyrakis et al., 2011; Vigeolas et al., 2011; Leiva-Eriksson et al., 2014). Vigeolas et al. (2011) overexpressed endogenous AtHb2 in developing seeds of Arabidopsis, which resulted in an increase in $\alpha$-linolenic acid and a $40 \%$ increase in the total fatty acid content. The increase was explained to be due to an elevated energy state and sucrose content of the seeds.

In this study, the Arabidopsis AtWRI1 and class 2-nsHb genes from Beta vulgaris (BvHb2) and Arabidopsis thaliana (AtHb2) were introduced by Agrobacterium mediated transformation into field cress for increasing the seed oil content.

\section{MATERIALS AND METHODS}

\section{Plant Material}

The field cress (L. campestre) seeds used in this study were originally collected by late Professor Arnulf Merker in Öland, Sweden and the accession number is NO94-7.

\section{Surface Sterilization and Germination of Seeds}

Prior to sowing, the seeds were surface sterilized in $3 \%$ calcium hypochlorite $\left(\mathrm{CaCl}_{2} \mathrm{O}_{2}\right)$ with Tween20, with shaking for $15 \mathrm{~min}$. The seeds were rinsed thoroughly with sterile water, sowed on germination medium as described by Ivarson et al. (2013) and allowed to germinate in light for 5 days.

\section{In vitro Culture Conditions}

All in vitro cultures were maintained in a growth chamber with a day length of $16 \mathrm{~h}$ at $33 \mu \mathrm{mol} \mathrm{m} \mathrm{m}^{-2} \mathrm{~s}^{-1}$ and a temperature of $21^{\circ} \mathrm{C}$ and a dark period of $8 \mathrm{~h}$ with a temperature of $18^{\circ} \mathrm{C}$. The transgenic lines and the WT plants were cultured under identical conditions, but covered with perforated plastic bags to avoid cross pollination. 


\section{Transformation Vectors}

Three different constructs were used for transformation by the Agrobacterium strain AGL-1: (1) AtWRI1-construct; (2) AtHb2construct; (3) $\mathrm{BvHb2}$-construct. The AtWRI1 gene according to AtWRINKLED1 (Cernac and Benning, 2004), AtHb2 according to class-2 nsHbs from Arabidopsis (accession no. NM_111887.2) and $\mathrm{BvHb} 2$ according to class-2 nsHbs from $B$. vulgaris (accession no. KF549982.1) were custom synthesized (Eurofins/MWG, Ebersberg, Germany or Epoch Life Signs, Inc., Missouri City, TX, USA) and then cloned into the transformation vector pBINPLUS/ARS (Belknap et al., 2008). All three target genes are under the seed specific promoter Fp1, generated from B. napus (Stalberg et al., 1993). After the sequence confirmation, the vectors were mobilized into the Agrobacterium strain AGL-1 for plant transformation, which was carried out according to the protocol by Ivarson et al. (2013).

\section{PCR Analysis}

Regenerated shoots that were of good growth vigor were analyzed through polymerase chain reaction (PCR) analysis. Total genomic DNA was extracted from the in vitro grown shoots by the CTAB method (Aldrich and Cullis, 1993). Successful integration of the transgenes nptII, AtWRI1, AtHb2, and BvHb2 was analyzed by PCR. The primers used for the $n p t I I$ gene was: $5^{\prime}-$ GCCCTGAATGAACTGCAGGACGAGGC-3' and $5^{\prime}$-GCAGGC ATCGCCATGGGTCACGACGA-3', yielding a product of $411 \mathrm{bp}$, for the AtWRI1 gene: 5'-CGGGATCCCTCATCCCCT TTTA-3' and 5'-CGGTGGTTCTTCCACGTACT- $3^{\prime}$ yielding a product of $1213 \mathrm{bp}$, for the AtHb2 gene: 5'-AGACATCCCC AAATACAGCC- $3^{\prime}$ and $5^{\prime}$-TGAAGACTTTAACAGCATGAGC$3^{\prime}$ yielding a product of $146 \mathrm{bp}$ and for the $\mathrm{BvHb2}$ gene: $5^{\prime}$ GCAAAATATCCCAGAATACAGCC- $3^{\prime}$ and $5^{\prime}$-TGGAACTTC CTCTGAATCCC-3' yielding a product of $106 \mathrm{bp}$.

\section{Southern Blot Analysis}

In order to further confirm the transgene integration and to determine the number of transgene copies in the transgenic lines, Southern blot analysis was performed. Approximately $20 \mu \mathrm{g}$ of genomic DNA, extracted from in vitro grown shoots using the CTAB method (Aldrich and Cullis, 1993), was digested with the BglII restriction enzyme. The probes were synthesized using the same primers as for the PCR analysis in accordance with Zhu et al. (2008). The non-radioactive DIG system was used for the Southern blot hybridization (Zhu et al., 2008).

\section{Western Blot Analysis}

Western blot analysis was conducted to identify the AtHb2 protein expression in the transgenic lines through SDSPAGE gel electrophoresis and immunoblotting. For protein extraction, soluble proteins were extracted from $1 \mathrm{mg}$ of ground seed material in $20 \mu \mathrm{l}$ of extraction buffer $(62.5 \mathrm{mM}$ Tris- $\mathrm{HCl}, \mathrm{pH} 7.5$ containing 2\% SDS, 10\% Glycerol, $1 \mathrm{mM}$ EDTA, $5 \mathrm{mM}$ dithiothreitol and $0.5 \%$ plant protease inhibitors [Sigma-Aldrich, St. Louis, MO, USA]) and centrifuged at $20.200 \mathrm{~g}$ at $4^{\circ} \mathrm{C}$ for $20 \mathrm{~min}$. The total protein content in each sample was determined by bicinchoninic acid (BCA; Pierce Biotechnology, Inc., Rockford, IL, USA) protein assay using bovine serum albumin (BSA) as standard. For protein immunoblots, equal amount $(20 \mu \mathrm{g})$ of extracted protein samples were separated by Bolt ${ }^{\mathrm{TM}} 4-12 \%$ Bis-Tris Plus gels (Invitrogen, Life Technologies, Carlsbad, CA, USA) under reducing conditions and transferred to polyvinylidene fluoride (PVDF) membrane using iBlot Gel Transfer Device (Program P0) (Invitrogen, Life Technologies, Carlsbad, CA, USA). The transferred membrane was blocked with SuperBlock T20 (PBS) blocking buffer (Thermo Fisher Scientific, Inc., Waltham, MA, USA) at room temperature with rocking for $1 \mathrm{~h}$, followed by incubation in the anti-AtHb2 primary antibody (1:1000; Agrisera) in the SuperBlock T20 (PBS) blocking buffer for $1 \mathrm{~h}$ at $22^{\circ} \mathrm{C}$. Then the membrane was washed 3 times with PBS Tween ${ }^{\circledR}-20$ (Thermo Fisher Scientific, Inc., Waltham, MA, USA) for $5 \mathrm{~min}$ each and probed with Novex ${ }^{\circledR}$ anti-rabbit secondary antibody conjugated with horseradish peroxidase at a 1:2000 dilution in SuperBlock T20 (PBS) blocking buffer. Detection was carried out with Novex ${ }^{\circledR}$ ECL chemiluminescent substrate reagent kit (\#WP20005; Invitrogen). MagicMark XP (\#LC5602; Invitrogen) Western Protein Standard was used to determine relative molecular weights.

\section{Quantitative Real Time PCR (qRT-PCR) analysis}

Immature pods were collected 28 days after flowering and total RNA was extracted using the RNeasy Plant Mini Kit (Qiagen, Hilden, Germany). Apart from some minor alterations, the manufacturer's protocol was followed for RNA extraction. The extracted RNA was treated with DNase (TURBO DNA-free (Ambion, Austin, TX, USA) to remove genomic DNA. First strand cDNA was synthesized from $1000 \mathrm{ng}$ RNA by using Superscript III First-Strand Synthesis Supermix for qRT-PCR (Invitrogen, Life Technologies, Carlsbad, CA, USA) in a $20 \mu \mathrm{l}$ reaction. The obtained $\mathrm{cDNA}$ was diluted five times and $3 \mu \mathrm{l}$ was used for each $20 \mu \mathrm{l}$ qRT-PCR reaction using BIO-RAD C1000 Thermal Cycler, CFX 96 Real-Time System (Foster City, CA, USA) with BIO-RAD iQ SYBR Green Supermix (Bio-Rad, Hercules, CA, USA). The PCR program used was $95^{\circ} \mathrm{C}$ for $10 \mathrm{~min}$ followed by 40 cycles of $95^{\circ} \mathrm{C}$ for $15 \mathrm{~s}, 63^{\circ} \mathrm{C}$ for $30 \mathrm{~s}$ and $72^{\circ} \mathrm{C}$ for $30 \mathrm{~s}$. To confirm product specificity, a melt curve analysis was included in the analysis. The primer pairs for the AtWRI1, $A t \mathrm{Hb} 2$, and $\mathrm{BvHb} 2$ genes (Supplementary Table S1) were chosen among several pairs tested for their efficiency and specificity. The TIP41-like reference gene (Supplementary Table S1) was used as a reliable reference in this study as reported by Lenser and Theissen (2013), Muhlhausen et al. (2013), and Ivarson et al. (2016). For each line, three biological replicates and three technical replicates were conducted.

\section{Plant Growth Conditions and Management}

Confirmed transgenic lines together with the WT plants were in vitro vernalized at $4^{\circ} \mathrm{C}$ for 8 weeks in a growth chamber with a light intensity of $30 \mu \mathrm{mol} \mathrm{m} \mathrm{m}^{-2} \mathrm{~s}^{-1}$ before they were 
planted in the biotron, in which the growing conditions were 16$\mathrm{h}$ photoperiod with $250 \mu \mathrm{mol} \mathrm{m} \mathrm{m}^{-2} \mathrm{~s}^{-1}$ light intensity, $21 / 18^{\circ} \mathrm{C}$ temperature (day/night) and $60 \%$ humidity. The plants were fertilized every 8 weeks with long-lasting granules $(\mathrm{N}: \mathrm{P}: \mathrm{K}=21$ : 3: 10) and watered regularly. Mature seeds were harvested and dried before threshing. The seeds were then stored at $4^{\circ} \mathrm{C}$ until further analysis.

\section{Oil Content Analysis}

Triplicates of pooled samples of three seeds per replicate were weighed and placed in glass tubes with addition of $1 \mathrm{ml} 0.15 \mathrm{M}$ acetic acid and $3.75 \mathrm{ml} \mathrm{MeOH}: \mathrm{CHCl}_{3}$ (2:1). The samples were then homogenized by IKA ${ }^{\circledR}$ T18 basic (ULTRA TURRAX ${ }^{\circledR}$ ), followed by addition of $1.25 \mathrm{ml} \mathrm{CHCl}_{3}$ and $0.9 \mathrm{ml} \mathrm{H}_{2} \mathrm{O}$. Then the samples were vortexed and centrifuged for $2 \mathrm{~min}$ at $3000 \mathrm{rpm}$ before $200 \mu \mathrm{l}$ of the chloroform phase was pipetted to a new tube. The tubes were then allowed to dry completely under nitrogen before $100 \mu \mathrm{l}$ hexane, 100 nmols of internal standard 17:0 (in methanol) and $2 \mathrm{ml}$ methylation solution (2\% $\mathrm{H}_{2} \mathrm{SO}_{4}$ in methanol) was added to the tubes. The tubes were left to methylate at $90^{\circ} \mathrm{C}$ for $1 \mathrm{~h}$. After methylation, the samples were left to cool down before $1 \mathrm{ml} \mathrm{H}_{2} \mathrm{O}$ and $600 \mu \mathrm{l}$ hexane was added. The samples were vortexed and centrifuged for $2 \mathrm{~min}$ at $2000 \mathrm{rpm}$ and finally, $200 \mu \mathrm{l}$ of the hexane phase was transferred to a GC vial with an insert. The samples were analyzed on an Agilent (model 7890A) gas chromatograph with a WCOT Fused Silica CP-Wax 58 column and a FID detector (Agilent technologies, Santa Clara, CA, USA).

\section{Experimental Design and Statistical Analysis}

The seed oil content was analyzed in triplicate samples with three seeds per replicate from the WT plants and the transgenic lines, respectively. In total, $10 \mathrm{WT}$ plants from $\mathrm{T}_{1}, 12 \mathrm{WT}$ plants from $\mathrm{T}_{2}$ and $17 \mathrm{WT}$ plants from $\mathrm{T}_{3}$ were analyzed. Each transgenic line corresponds to one plant. The seed oil content was calculated based on the peak areas in the chromatograms from the GC analysis. The mean seed oil content and the standard deviation were calculated. The data was analyzed by Fisher pairwise comparisons with a significance level of $95 \%$, using the Minitab program.

The seed weight was analyzed from triplicate samples with 100 seeds per replicate from a WT plant and the transgenic lines. The mean seed weight and the standard deviation were calculated. The seed weights were compared using Fisher pairwise comparisons with a significance level of $95 \%$ in the Minitab program.

The seed oil composition of triplicate samples with three seeds per replicate was calculated based on the peak areas in the chromatograms from the GC analysis. The mean and standard deviation were decided and the data was analyzed with Tukey pairwise comparisons with a significance level of $95 \%$ using Minitab.

The gene expression was analyzed in three biological replicates per WT plant or transgenic line. Three technical replicates per biological replicate were analyzed in the qRT-PCR analysis. The relative expression level was calculated and the data was analyzed with Tukey pairwise comparisons with a significance level of $95 \%$, using the Minitab program.

\section{RESULTS}

\section{Molecular Analysis of Transgenic Lines}

Polymerase chain reaction analysis on the genomic DNA from putative transgenic lines showed successful integration of the AtWRI1 gene in 19 lines, AtHb2 in 20 lines and $B v H b 2$ in 23 lines. All the transgenic lines harbor also the nptII gene for selection of transformants (Supplementary Figure S1).

Southern blot analysis showed that hybridization with the $n p t I I$ probe gave rise to clear bands, indicating a stable integration of the T-DNA into the field cress genome. As shown in Figure 1A, the copy number of the nptII gene ranged from 1 to 4 , with 4 out of 10 analyzed lines showing single copy integration of the transgene. The AtWRI1 overexpressing line 2 (lane 1, Figure 1A) and the $B v H b 2$ overexpressing line 5 (lane 8 , Figure 1A) were two of the lines that were further analyzed up to $\mathrm{T}_{4}$.

All AtHb2-expressing lines showed protein expression of the $A t H b 2$ gene with varying band intensity in both first and third generations, while no AtHb2 protein expression was found in the WT seeds in both generations (Figure 1B). This indicates the $A t \mathrm{Hb} 2$ gene was stably expressed in the subsequent generations.

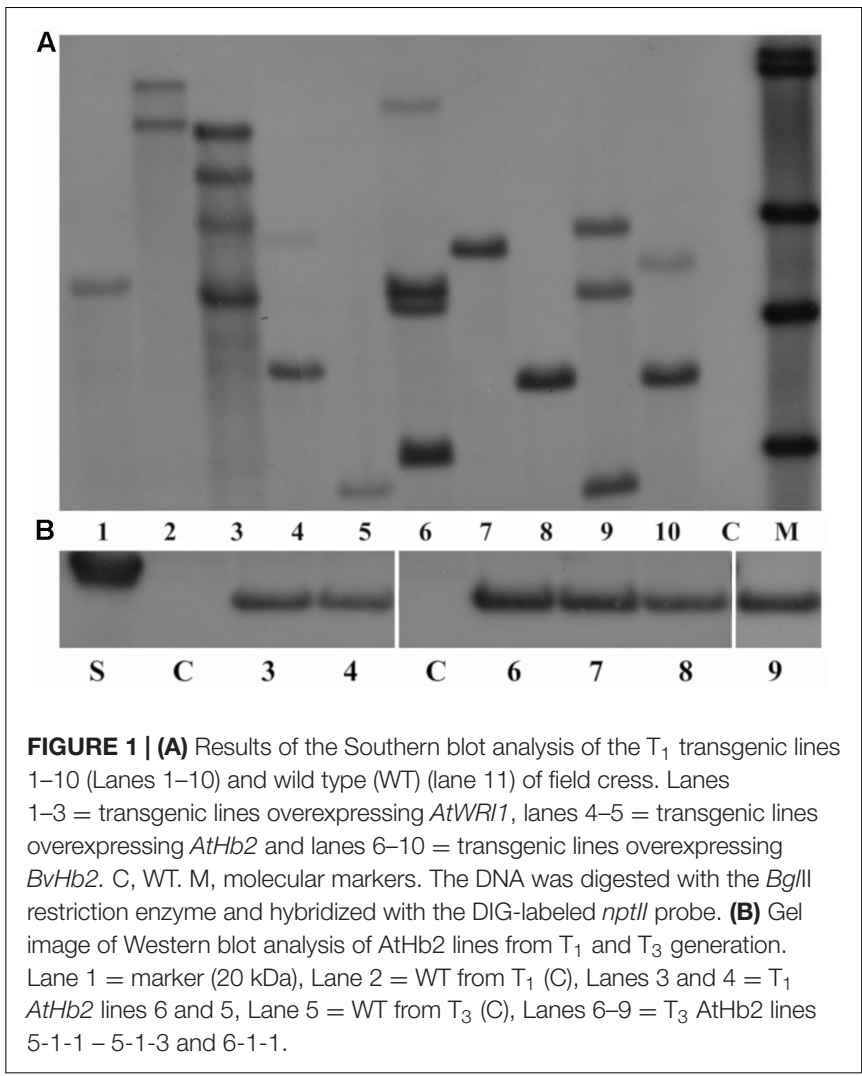




\section{Plant Performance and Seed Oil Content}

When grown in biotron, the transgenic plants did not show any phenotypic deviations from the WT plants, in terms of plant height, flowering time, seed setting and seed development.

To evaluate the influence of the expression of the transgenes on seed oil content, total seed fatty acid content was analyzed in mature seeds using gas chromatography analysis. The lines exhibiting the highest levels of oil contents in $\mathrm{T}_{1}$ were further evaluated in the subsequent generations up to $\mathrm{T}_{4}$. Since the oil content is easily affected by environmental factors, all transgenic lines including the WT were grown under identical conditions in the biotron. To simplify the table, only the lines showing the increased oil content are presented in Table 1. For all three constructs, transgenic lines with significantly increased seed oil content were found in $\mathrm{T}_{1}$ (Table 1). For the lines overexpressing the AtWRI1 gene, two transgenic lines showed greater oil content increase than the other lines in $\mathrm{T}_{1}$. Of the two lines, one had an oil content of $24.3 \%$ compared to $21.8 \%$ in the $\mathrm{WT}$, generating an oil increase of $11.4 \%$. Another line showed a greater oil increase of $17.9 \%$, with the oil content of $25.7 \%$. In $\mathrm{T}_{2}$, the two lines showing highest oil contents had an increased oil content of 18.1 and $29.9 \%$, respectively compared to the WT. The oil content of the $\mathrm{T}_{3}$ generation was generally lower for both WT and AtWRI1 lines compared to the $T_{1}$ and $T_{2}$ generations. The two lines with greatest increase in seed oil content had the oil content of 22.4 and $23.6 \%$, respectively compared to $19.9 \%$ for the WT, generating an oil increase of 12.4 and $18.3 \%$, respectively (Table 1).

For the transgenic lines harboring the AtHb2 gene, four lines showed significantly increased oil contents of 10.4, 11.7, 13.4, and $18.9 \%$, respectively, compared to the $\mathrm{WT}$ in $\mathrm{T}_{1}$. In $\mathrm{T}_{2}$, lines originating from lines 5 and 6 in $\mathrm{T}_{1}$ showed a significant increase in oil content. However, the increase was lower in $\mathrm{T}_{2}$ compared to $\mathrm{T}_{1}$, with an increase of 7.8 and $14.1 \%$, respectively for the two lines. The oil content in $\mathrm{T}_{3}$ was generally lower for both transgenic lines and WT; however, the increase in oil content was higher in $\mathrm{T}_{3}$ compared with $\mathrm{T}_{1}$ and $\mathrm{T}_{2}$. The three individual seed lines showing the highest oil increase ranged from 16.4 to $20.2 \%$ (Table 1).

Transgenic lines overexpressing the $\mathrm{BvHb2}$ gene showed the higher oil increases in $\mathrm{T}_{1}$ compared to the lines transformed with the other two constructs. The best performing line had an oil content of $27.4 \%$ compared to $21.8 \%$ in WT, generating an oil increase of $25.9 \%$. The other three lines had the oil content increased by $15.3,18.9$, and $23.9 \%$ respectively. However, the same high level of increase was not detected in the subsequent generations. The highest increase found in $\mathrm{T}_{2}$ was 12.3 and $16.7 \%$ in $\mathrm{T}_{3}$.

\section{Seed Weight}

Seed weight differs in some cases, for instance, the seed weight of the third generation transgenic lines overexpressing AtWRI1 (1-1-3 and 2-1-1) was significantly higher (increased by 3.5 and $12.4 \%$, respectively), while two of the lines (1-1-1 and 1-1-2) were significantly lower (decreased by 8.4 and $7.6 \%$, respectively) than the WT (Table 2). Regarding the AtHb2 overexpressing lines, one line in the third generation (5-1-3) showed a modest, but significant increase in seed weight by $3.6 \%$, while the other three lines (5-1-1, 5-1-2, and 6-1-1) showed a significantly lower seed weight compared to the WT. A significant increase in seed weight was also seen in one line (9-1-2) of third generation $\mathrm{B} v \mathrm{Hb}$ 2-overexpressing plants, while two of the remaining lines showed a decrease (Table 2).

TABLE 1 | Seed oil content and percentage of increase in seed oil content in three generations of transgenic lines of field cress overexpressing AtWRI1, $A t H b 2$, and $B v H b 2$ genes, respectively.

\begin{tabular}{|c|c|c|c|c|c|c|c|c|}
\hline \multicolumn{3}{|c|}{ AtWRI1 } & \multicolumn{3}{|c|}{ AtHb2 } & \multicolumn{3}{|c|}{$\mathrm{BvHb2}$} \\
\hline Gen./line & Oil content $(\%)^{*}$ & Increase (\%) & Gen./line & Oil content $(\%)^{*}$ & Increase (\%) & Gen./line & Oil content $(\%)^{*}$ & Increase (\%) \\
\hline T1 & & & $\mathrm{T} 1$ & & & T1 & & \\
\hline $\mathrm{WT}^{* *}$ & $21.8 \pm 0.7 c$ & & WT & $21.8 \pm 0.7 c$ & & WT & $21.8 \pm 0.7 c$ & \\
\hline 1 & $25.7 \pm 0.4 \mathrm{a}$ & 17.9 & 5 & $24.0 \pm 0.5 b$ & 10.4 & 9 & $27.4 \pm 0.2 \mathrm{a}$ & 25.9 \\
\hline 2 & $24.3 \pm 1.0 \mathrm{ab}$ & 11.4 & 6 & $25.9 \pm 0.6 \mathrm{a}$ & 18.9 & 10 & $25.9 \pm 2.0 \mathrm{ab}$ & 18.9 \\
\hline 3 & $23.8 \pm 0.9 b$ & 9.2 & 7 & $24.7 \pm 0.8 \mathrm{ab}$ & 13.4 & 11 & $27.0 \pm 0.3 \mathrm{ab}$ & 23.9 \\
\hline 4 & $23.4 \pm 1.1 b$ & 7.3 & 8 & $24.4 \pm 0.4 b$ & 11.7 & 12 & $25.1 \pm 1.0 \mathrm{~b}$ & 15.3 \\
\hline T2 & & & T2 & & & T2 & & \\
\hline $\mathrm{WT}^{* *}$ & $21.4 \pm 1.7 b$ & & WT & $21.4 \pm 1.7 b$ & & WT & $21.4 \pm 1.7 \mathrm{a}$ & \\
\hline $1-1$ & $25.3 \pm 1.5 \mathrm{a}$ & 18.1 & $5-1$ & $24.4 \pm 1.7 \mathrm{a}$ & 14.1 & $9-1$ & $24.0 \pm 1.0 \mathrm{a}$ & 12.3 \\
\hline $2-1$ & $27.8 \pm 4.2 \mathrm{a}$ & 29.9 & $6-1$ & $23.1 \pm 1.5 \mathrm{a}$ & 7.8 & $10-1$ & $21.7 \pm 2.0 \mathrm{a}$ & 1.4 \\
\hline T3 & & & T3 & & & T3 & & \\
\hline $\mathrm{WT}^{* *}$ & $19.9 \pm 1.3 c$ & & WT & $19.9 \pm 1.3 b$ & & WT & $19.9 \pm 1.3 \mathrm{c}$ & \\
\hline $1-1-1$ & $20.4 \pm 2.7 \mathrm{bc}$ & 2.3 & $5-1-1$ & $23.6 \pm 2.4 \mathrm{a}$ & 18.4 & $9-1-1$ & $22.1 \pm 0.3 a b$ & 10.9 \\
\hline $1-1-2$ & $23.6 \pm 1.0 \mathrm{a}$ & 18.3 & $5-1-2$ & $23.9 \pm 0.7 \mathrm{a}$ & 20.2 & $9-1-2$ & $20.5 \pm 0.8 b c$ & 3 \\
\hline $1-1-3$ & $22.4 \pm 0.7 \mathrm{ab}$ & 12.4 & $5-1-3$ & $23.2 \pm 0.9 a$ & 16.4 & $9-1-3$ & $23.2 \pm 0.4 a$ & 16.7 \\
\hline $2-1-1$ & $20.2 \pm 0.8 b c$ & 1.2 & $6-1-1$ & $20.1 \pm 1.0 \mathrm{~b}$ & 0.9 & $9-1-4$ & $22.6 \pm 0.9 a$ & 13.7 \\
\hline
\end{tabular}

Results represent mean $\pm S D$ from three replicates of pooled seeds per transgenic line, $10 \mathrm{WT}$ plants from $T_{1}$, 12 WT plants from $T_{2}$, and $17 \mathrm{WT}$ plants from $T_{3}$

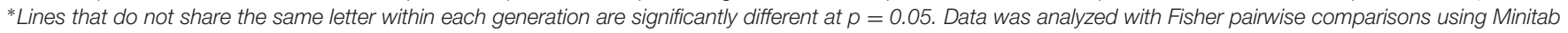
program. ** The oil content of WT plants ranged from 20.1 to $22.7 \%$ in $T_{1}, 18.6$ to $24.5 \%$ in $T_{2}$, and 16.9 to $22.1 \%$ in $T_{3}$. 
TABLE 2 | Seed weight (mean \pm SD* from three replicates per line) in three generations of field cress lines overexpressing AtWRI1, AtHb2, and BvHb2, respectively.

\begin{tabular}{|c|c|c|c|c|c|}
\hline AtWRI1 & mg/100 seeds* & AtHb2 & mg/100 seeds* & $\mathrm{BvHb2}$ & mg/100 seeds* \\
\hline T1 & & T1 & & T1 & \\
\hline WT & $305.1 \pm 2.1 \mathrm{a}$ & WT & $305.1 \pm 2.1 \mathrm{a}$ & WT & $305.1 \pm 2.1 \mathrm{a}$ \\
\hline 1 & $310.3 \pm 4.9 \mathrm{a}$ & 5 & $249.8 \pm 0.2 c$ & 9 & $300.9 \pm 3.2 \mathrm{a}$ \\
\hline 2 & $308.9 \pm 2.1 \mathrm{a}$ & 6 & $301.2 \pm 1.4 b$ & 10 & $268.2 \pm 4.3 b$ \\
\hline T2 & & T2 & & T2 & \\
\hline WT & $278.3 \pm 1.0 \mathrm{a}$ & WT & $278.3 \pm 1.0 \mathrm{a}$ & WT & $278.3 \pm 1.0 \mathrm{a}$ \\
\hline $1-1$ & $258.4 \pm 1.4 b$ & $5-1$ & $266.1 \pm 5.2 b$ & $9-1$ & $263.3 \pm 2.5 b$ \\
\hline $2-1$ & $\mathrm{NA}^{* *}$ & $6-1$ & $259.9 \pm 2.4 b$ & $10-1$ & $263.5 \pm 5.4 b$ \\
\hline T3 & & T3 & & T3 & \\
\hline WT & $301.9 \pm 3.3 c$ & WT & $301.9 \pm 3.3 b$ & WT & $301.9 \pm 3.3 b$ \\
\hline $1-1-1$ & $276.4 \pm 9.2 \mathrm{~d}$ & $5-1-1$ & $253.1 \pm 1.4 \mathrm{~d}$ & $9-1-1$ & $303.2 \pm 1.6 b$ \\
\hline $1-1-2$ & $279.0 \pm 1.8 d$ & $5-1-2$ & $289.7 \pm 1.2 \mathrm{c}$ & $9-1-2$ & $309.9 \pm 1.9 a$ \\
\hline $1-1-3$ & $312.6 \pm 0.4 b$ & $5-1-3$ & $312.8 \pm 1.1 \mathrm{a}$ & $9-1-3$ & $289.7 \pm 1.8 c$ \\
\hline $2-1-1$ & $339.2 \pm 1.4 \mathrm{a}$ & $6-1-1$ & $295.4 \pm 2.9 c$ & $9-1-4$ & $285.9 \pm 1.5 c$ \\
\hline
\end{tabular}

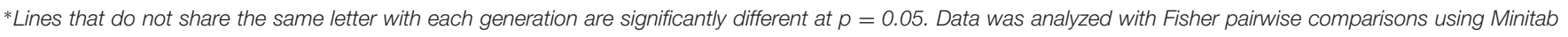
program.

**Not available due to insufficient number of seeds.

Further analysis on changes in seed oil content and seed weight showed no significant relation between these two alterations in transgenic lines of field cress (Figure 2).

\section{Seed Oil Composition}

The seed oil composition in the transgenic lines was in general not different from the oil composition of the WT. Minor deviations were found, for instance, the AtWRI1-expressing line 1-1-2 (Table 3) showed a significant decrease in the levels of 18:1, 18:2, 20:1, and 22:1, however, this change was not seen among the other AtWRI1-expressing lines. The only deviation found among the $A t H b 2$-overexpressing lines was a significant decrease in 22:1 in line 5-1-2. One BvHb2-overexpressing lines (9-1-2) had a significantly lower level of 18:2, 20:1 and 22:1 fatty acids, and a second line (9-1-1) had significantly lower levels of 18:3 and 22:1 fatty acids, however, no clear trend was seen among the lines.

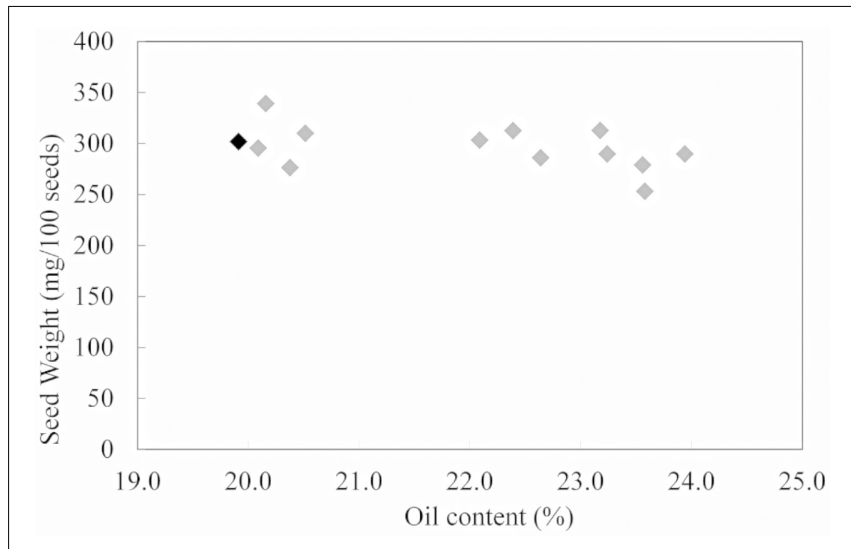

FIGURE 2 | Correlation analysis between seed weight and seed oil content in WT (black) and transgenic lines of field cress (gray).

\section{Quantitative Real Time PCR (qRT-PCR) Analysis}

Transgene expression of five transgenic $\mathrm{T}_{3}$ lines from each construct was analyzed by qRT-PCR. In order to compare transgene expression levels of AtWRI1, AtHb2 and BvHb2, transgenic lines with both moderate and higher increase in oil content were chosen for analysis. In the AtWRI1 overexpressing lines, overexpression of AtWRI1 was found in all transgenic lines, with a relative expression level up to over 90.000 -fold higher than in the WT (Figure 3). The line having the lowest relative AtWRI1 expression level corresponded to the lowest oil content among the lines analyzed, indicating the gene expression level of the transgene positively correlated with the seed oil content.

The relative expression level of $A t H b 2$ was higher in the transgenic lines compared to the WT, with a fold-increase ranging between 84 and 114 .

A much lower transgene expression level was detected in the $\mathrm{BvHb} 2$ overexpressing lines among the three types of transgenic lines. The transgenic lines showed a relative expression level increased by a fold-change of 9.3 to 13.7, with a positive correlation between oil content and gene expression level.

\section{DISCUSSION}

As sustainable resources, plants have a great potential to provide tailor-made oil qualities for a bioeconomy-based society. However, the amount of plant oils produced and the variation of oil qualities available today are very limited, mainly due to the limited oil crop species available in commercial production, which are restricted to certain climate conditions. The need for developing new and high yielding oil crops with novel and favorable oil compositions, which can be adapted to certain climate conditions, such as cold regions or marginal lands is thus crucial. Owing to its favorable agronomic characteristics, 
TABLE 3 | Seed oil composition (\%, mean \pm SD* from three replicates per line) in T3 transgenic lines overexpressing AtWRI1, AtHb2, and BvHb2 genes, respectively, and wild type of field cress.

\begin{tabular}{|c|c|c|c|c|c|c|}
\hline Line & $18: 1$ & 18:2 & $18: 3$ & $20: 1$ & $22: 1$ & 24:0 \\
\hline \multicolumn{7}{|c|}{ AtWRI1 } \\
\hline WT & $11.8 \pm 0.7 \mathrm{a}$ & $6.7 \pm 0.2 \mathrm{a}$ & $28.7 \pm 0.6 \mathrm{a}$ & $4.1 \pm 0.2 b$ & $26.5 \pm 0.6 a$ & $2.0 \pm 0.5 a$ \\
\hline $1-1-1$ & $10.7 \pm 0.9 a b$ & $6.2 \pm 0.2 \mathrm{ab}$ & $27.3 \pm 0.5 a$ & $3.6 \pm 0.5 b$ & $23.4 \pm 0.2 b$ & $2.1 \pm 0.2 \mathrm{a}$ \\
\hline $1-1-2$ & $9.4 \pm 0.3 b$ & $5.6 \pm 0.6 b$ & $27.6 \pm 1.5 \mathrm{a}$ & $3.2 \pm 0.3 a$ & $23.3 \pm 0.8 b$ & $2.8 \pm 2.3 a$ \\
\hline $1-1-3$ & $12.0 \pm 0.5 \mathrm{a}$ & $6.1 \pm 0.2 \mathrm{ab}$ & $27.4 \pm 0.2 \mathrm{a}$ & $3.9 \pm 0.2 b$ & $23.8 \pm 0.2 b$ & $1.8 \pm 1.0 \mathrm{a}$ \\
\hline $2-1-1$ & $10.2 \pm 0.5 a b$ & $5.9 \pm 0.4 \mathrm{ab}$ & $28.8 \pm 0.7 \mathrm{a}$ & $3.4 \pm 0.1 b$ & $25.4 \pm 0.1 \mathrm{a}$ & $1.9 \pm 0.2 a$ \\
\hline \multicolumn{7}{|c|}{$A t H b 2$} \\
\hline WT & $11.8 \pm 0.7 \mathrm{ab}$ & $6.7 \pm 0.2 \mathrm{ab}$ & $28.7 \pm 0.6 \mathrm{ab}$ & $4.1 \pm 0.2 \mathrm{ab}$ & $26.5 \pm 0.6 \mathrm{a}$ & $2.0 \pm 0.5 a$ \\
\hline $5-1-1$ & $14.0 \pm 1.5 \mathrm{a}$ & $6.3 \pm 0.1 b$ & $27.4 \pm 1.4 a b$ & $4.6 \pm 0.4 \mathrm{a}$ & $26.4 \pm 0.6 \mathrm{a}$ & $1.4 \pm 1.2 \mathrm{a}$ \\
\hline $5-1-2$ & $14.1 \pm 0.4 a$ & $6.9 \pm 0.3 \mathrm{ab}$ & $26.5 \pm 1.3 b$ & $4.6 \pm 0.1 \mathrm{a}$ & $20.9 \pm 1.2 b$ & $1.2 \pm 0.9 a$ \\
\hline $5-1-3$ & $12.6 \pm 0.7 a b$ & $6.7 \pm 0.2 \mathrm{ab}$ & $30.0 \pm 0.8 a$ & $4.7 \pm 0.1 \mathrm{a}$ & $26.5 \pm 0.1 \mathrm{a}$ & $1.2 \pm 0.8 a$ \\
\hline $6-1-1$ & $11.0 \pm 0.5 b$ & $7.3 \pm 0.3 \mathrm{a}$ & $29.7 \pm 0.3 \mathrm{a}$ & $4.0 \pm 0.2 \mathrm{ab}$ & $27.2 \pm 0.3 \mathrm{a}$ & $1.8 \pm 0.4 a$ \\
\hline \multicolumn{7}{|c|}{ BvHb2 } \\
\hline WT & $11.8 \pm 0.7 \mathrm{ab}$ & $6.7 \pm 0.2 \mathrm{a}$ & $28.7 \pm 0.6 \mathrm{a}$ & $4.1 \pm 0.2 \mathrm{a}$ & $26.5 \pm 0.6 \mathrm{a}$ & $2.0 \pm 0.5 a$ \\
\hline $9-1-1$ & $12.6 \pm 0.4 a$ & $6.4 \pm 0.1 \mathrm{ab}$ & $26.9 \pm 0.4 b$ & $3.9 \pm 0.1 \mathrm{ab}$ & $20.7 \pm 0.7 b$ & $1.9 \pm 0.0 \mathrm{a}$ \\
\hline $9-1-2$ & $10.9 \pm 0.2 b$ & $5.9 \pm 0.2 b$ & $27.8 \pm 0.3 \mathrm{ab}$ & $3.3 \pm 0.1 b$ & $20.0 \pm 1.3 b$ & $1.9 \pm 0.3 a$ \\
\hline $9-1-3$ & $11.1 \pm 0.0 \mathrm{~b}$ & $6.4 \pm 0.1 \mathrm{ab}$ & $28.4 \pm 1.0 \mathrm{ab}$ & $4.0 \pm 0.1 \mathrm{a}$ & $24.8 \pm 0.4 a$ & $1.7 \pm 0.1 \mathrm{a}$ \\
\hline $9-1-4$ & $11.9 \pm 0.9 a b$ & $6.3 \pm 0.2 \mathrm{ab}$ & $28.7 \pm 0.5 a$ & $4.3 \pm 0.4 \mathrm{a}$ & $26.1 \pm 0.4 \mathrm{a}$ & $1.5 \pm 0.1 \mathrm{a}$ \\
\hline
\end{tabular}

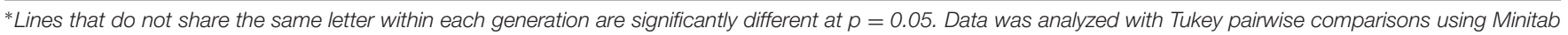
program.

the wild field cress has potential to be domesticated into a novel oilseed crop. As it is biennial, it can be cultivated as a catch crop with less need for tillage and reduced nutrient leaching, thus having environmental benefits. Also, due to its high winter hardiness, it can be cultivated in regions where winter is harsh.

Several attempts to alter the oil content of various crops have been made, both by upregulation of the key enzymes in the oil biosynthesis (Jako et al., 2001; Lardizabal et al., 2008; Liu et al., 2015) and regulations of some important transcription factors involved in the oil biosynthesis (Liu et al., 2010; Shen et al., 2010; An and Suh, 2015). For instance, overexpression of DGAT in Arabidopsis yielded seed oil content increases of between 9 and $12 \%$ on a dry weight basis (Jako et al., 2001), while the seed oil increases ranging between 10 and $40 \%$ was generated by BnWRI1-overexpression in Arabidopsis (Liu et al., 2010).

In this study, Arabidopsis WRI1 gene and nsHb genes from Arabidopsis and sugar beet were individually expressed under the seed specific promoter in field cress to investigate whether overexpression of these genes could increase the seed oil content in the target wild species. Our results showed that overexpression of the AtWRI1, AtHb2, and $B v H b 2$ gene could increase the oil content up to $29.9,20.2$, and $25.9 \%$, respectively in field cress. A similar increase has been demonstrated in camelina, where a seed-specific overexpression of AtWRI1 yielded a 14\% increase in total seed oil content (An and Suh, 2015). An even higher increase has been shown in maize where ZmWRI1overexpression generated an average increase in seed oil content of $30.6 \%$ (Shen et al., 2010). The $20.2 \%$ increase in seed oil content of AtHb2-overexpressing lines of field cress achieved in this study is lower compared to the increase generated in a study by Vigeolas et al. (2011), in which overexpression of AtHb2 in Arabidopsis led to a $40 \%$ increase in fatty acid content in Arabidopsis. This is probably due to the different species studied.

In $\mathrm{T}_{1}$, the highest increases in the oil content were found in the lines overexpressing the $\mathrm{BvHb} 2$ gene. However, the high increase was not maintained in the subsequent generations, indicating likely an unstable expression of the transgene. This can be reflected in the qRT-PCR result where it showed a much lower expression of the $\mathrm{BvHb} 2$ gene, compared to these of the AtWRI1 and $A t H b 2$ genes in other transgenic lines.

The phenotypic performance did not differ between the transgenic plants and the WT plants under biotron conditions, namely no deviations in flowering time, seed setting or seed development were found in this study. This is in accordance with the study where B. napus WRI1 was overexpressed in Arabidopsis, leading to seed oil content increases of 10-40\% (Liu et al., 2010) and the study by An and Suh (2015) mentioned above.

Seed weight increases have been reported in transgenic Arabidopsis lines expressing BnWRI1 (Liu et al., 2010), and in AtWRI1-expressing lines of camelina (An and Suh, 2015). In this study, significant increases in seed weight were also observed in two of the third generation field cress lines overexpressing AtWRI1. However, the seed weights of two of the remaining $\mathrm{T}_{3}$ AtWRI1-expressing lines were significantly lower compared to the WT. The AtHb2- and BvHb2-expressing lines both had one $\mathrm{T}_{3}$ generation line with a significantly higher seed weight compared to the WT, while all the remaining $\mathrm{T}_{3}$ lines showed significant decreases or no differences in seed weight. No correlation between seed weight and seed oil content is seen in this study since the lines with the highest increases in seed oil content showed both increases and decreases in seed weight in comparison to the WT. The different degrees of increase in seed weight by the same homologous gene shown in different 

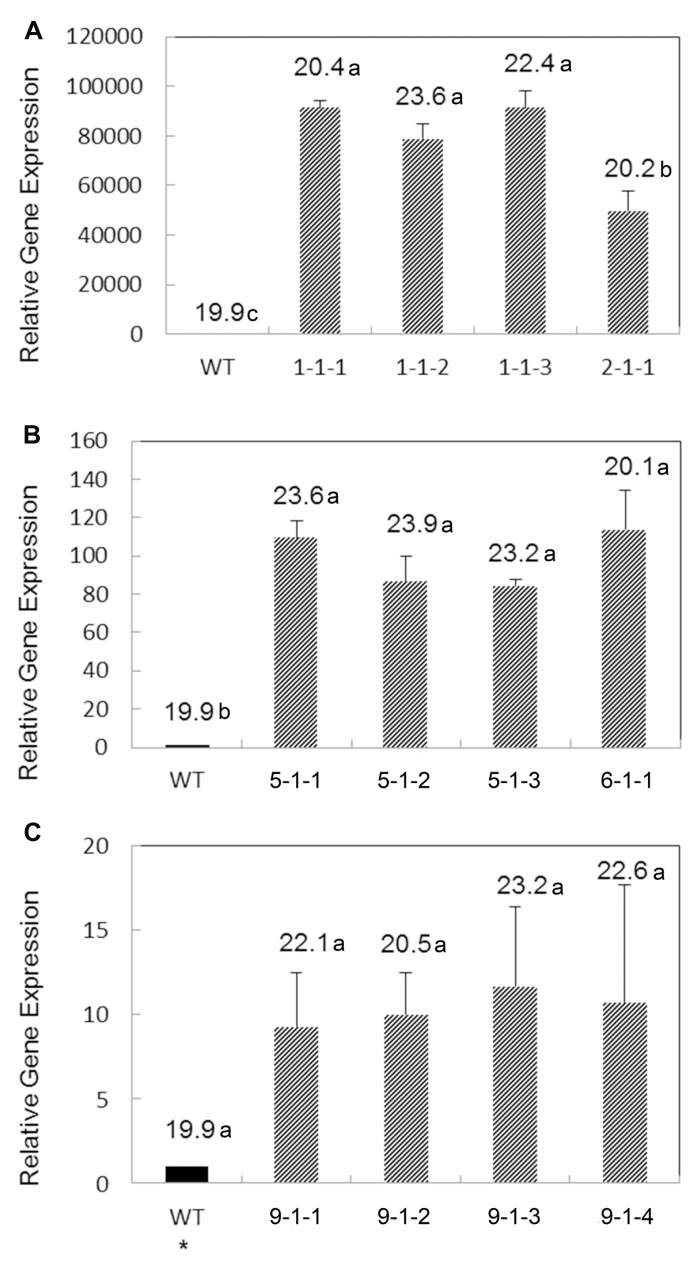

FIGURE 3 | Relative gene expression levels of the AtWRI1 (A), AtHb2 (B), and $\mathrm{BvH}_{\mathrm{b} 2}$ (C) genes in immature seeds of $\mathrm{T}_{3}$ transgenic lines in comparison with the WT. Results are means from three biological replicates with three technical replicates per biological replicate. Error bars represent standard deviation (SD). Figures above the bars represent the mean oil content (\%) in the respective lines. Bars that do not share the same letter are significantly different at $p=0.05$. Data was analyzed with Tukey pairwise comparison using Minitab program. *Estimated value since no expression of $\mathrm{BvHb2}$ in WT, which was generated by dividing the lowest expression value of a transgenic line by 10 . studies might be partially due to the position effect of transgene integration in the genome. It may also indicate a complicated relationship between oil increase and seed weight, as shown by Xu et al. (2008) where seed-specific expression of Tropaeolum majus diacylglycerol acyltransferase 1 (DGAT1) resulted in increased seed weight when expressed in Arabidopsis but not in B. napus. Vigeolas et al. (2011) did not report on any change in seed weight in AtHb2-overexpressing lines of Arabidopsis.

The seed oil composition of AtWRI1-expressing lines was not significantly different from the oil composition of the WT in this study. This is in line with the result reported by $\mathrm{Hu}$ et al. (2013) where the oil content was not correlated with fatty acid composition by comparing seven lines in rapeseed. However, the effects on oil composition of WRI1 overexpression reported in other studies vary depending on the origin of the WRI1 gene and the target species. For instance, in camelina, overexpression of AtWRI1 generated a seed oil composition with decreased levels of oleic acid (18:1) and eicosenoic acid (20:1), and increased levels of linoleic acid (18:2) and linolenic acid (18:3) (An and Suh, 2015). When AtWRI1 was infiltrated into Nicotiana benthamiana, a decrease in stearic acid (18:0) and 18:2 and an increase in 18:3 were found (Vanhercke et al., 2013), while no significant changes in oil composition was detected in ZmWRI1-overexpressing seeds of maize (Shen et al., 2010) or AtWRI1-overexpressing seeds of Arabidopsis (Cernac and Benning, 2004; van Erp et al., 2014). These results may suggest a difference in the enzyme activity depending on origin of the transgene and the transgene recipient as well as the position effect of transgene integration into the host genome.

In the study by Vigeolas et al. (2011), AtHb2 overexpression in Arabidopsis caused a change in the oil composition of the transgenic lines in comparison to the WT. The level of 20:1, which is a marker for storage TAG formation in Arabidopsis (Lemieux et al., 1990), was increased by $20-60 \%$. Also, increases in 18:2 and $18: 3$ and the 18:2/18:1 and 18:3/18:2 ratios were seen. However, in the present study, neither $\mathrm{AtHb2}$ - nor $\mathrm{BvHb2}$-overexpression resulted in any significant alterations in the seed oil composition of the transgenic field cress lines compared to the WT. This may also be species-dependent.

To further increase the seed oil content in field cress, a trial incorporating multigene engineering with a push-pull-protectapproach (Vanhercke et al., 2013) would be interesting to test in the future. Synergistic effects on seed oil content in Arabidopsis have also been reported by van Erp et al. (2014) when seed specific co-expression of WRI1 (push) and DGAT1 (pull) was combined with a mutation or downregulation of the SUGARDEPENDENT1 lipase gene. Furthermore, to combine the higholeic acid field cress lines generated in our previous study as stated above with an increase in the seed oil content would be beneficial for food processing or industrial applications since the oil would be more stable in high temperatures, and thus have a longer shelf-life.

\section{CONCLUSION}

We have developed transgenic lines of field cress with up to $29.9 \%$ increase in seed oil content by overexpressing three different target genes. Thus, this study shows the potential for the wild species $L$. campestre to be domesticated into a future highyielding oil- and catch crop.

\section{AUTHOR CONTRIBUTIONS}

EI participated in the design of the experiment, performed the majority of the experimental work, AA performed some experimental work, NL-E prepared the hemoglobin transformation vectors and participated in writing of the manuscript, SK performed the protein analysis and 
participated in writing of the manuscript, LB participated in writing of the manuscript and L-HZ designed and coordinated the project and prepared the AtWRI1 construct. EI and L-HZ wrote the manuscript.

\section{FUNDING}

This work is a part of the MISTRA-Biotech program (http://www.slu.se/en/collaborative-centres-and-projects/mistrabiotech), which is financed by MISTRA (The foundation for strategic environmental research) and SLU (Swedish University of Agricultural Sciences). The project was initiated by PlantLink seed money.

\section{ACKNOWLEDGMENTS}

We would like to thank Per Hofvander for providing the synthesized AtWRI1 gene, and Helén Lindgren and Mirela

\section{REFERENCES}

Aldrich, J., and Cullis, C. (1993). RAPD analysis in flax: optimization of yield and reproducibility using klenTaq 1 DNA polymerase, chelex 100, and gel purification of genomic DNA. Plant Mol. Biol. Rep. 11, 128-141. doi: 10.1007/ BF02670471

Al-Shehbaz, I. A. (1986). The genera of Lepidieae (cruciferae; Brassicaceae) in the southeastern United States. J. Arnold Arbor. 67, 265-311. doi: 10.5962/bhl.part .27392

An, D., and Suh, M. C. (2015). Overexpression of Arabidopsis WRI1 enhanced seed mass and storage oil content in Camelina sativa. Plant Biotechnol. Rep. 9, 137-148. doi: 10.1007/s11816-015-0351-x

Appleby, C. A., Bogusz, D., Dennis, E. S., and Peacock, W. J. (1988). A role for haemoglobin in all plant roots? Plant Cell Environ. 11, 359-367. doi: 10.1111/j. 1365-3040.1988.tb01360.x

Belknap, W., Rockhold, D., and McCue, K. (2008). pBINPLUS/ARS: an improved plant transformation vector based on pBINPLUS. Biotechniques 44, 753-756. doi: 10.2144/000112731

Carlsson, A. S., Yilmaz, J. L., Green, A. G., Stymne, S., and Hofvander, P. (2011). Replacing fossil oil with fresh oil - with what and for what? Eur. J. Lipid Sci. Technol. 113, 812-831. doi: 10.1002/ejlt.201100032

Cernac, A., and Benning, C. (2004). WRINKLED1 encodes an AP2/EREB domain protein involved in the control of storage compound biosynthesis in Arabidopsis. Plant J. 40, 575-585. doi: 10.1111/j.1365-313X.2004.02235.x

Focks, N., and Benning, C. (1998). wrinkled1: a novel, low-seed-oil mutant of Arabidopsis with a deficiency in the seed-specific regulation of carbohydrate metabolism. Plant Physiol. 118, 91-101. doi: 10.1104/pp.118.1.91

Hill, R. D. (2012). Non-symbiotic haemoglobins-What's happening beyond nitric oxide scavenging? AoB Plants 2012, ls004. doi: 10.1093/aobpla/pls004

Hu, Z.-Y., Hua, W., Zhang, L., Deng, L.-B., Wang, X.-F., Liu, G.-H., et al. (2013). Seed structure characteristics to form ultrahigh oil content in rapeseed. PLoS One 8:e62099. doi: 10.1371/journal.pone.0062099

Ivarson, E., Ahlman, A., Lager, I., and Zhu, L. H. (2016). Significant increase of oleic acid level in the wild species Lepidium campestre through direct gene silencing. Plant Cell Rep. 35, 2055-2063. doi: 10.1007/s00299-016-2016-9

Ivarson, E., Ahlman, A., Li, X., and Zhu, L.-H. (2013). Development of an efficient regeneration and transformation method for the new potential oilseed crop Lepidium campestre. BMC Plant Biol. 13:115. doi: 10.1186/1471-2229-13-115

Jain, R. K., Coffey, M., Lai, K., Kumar, A., and MacKenzie, S. L. (2000). Enhancement of seed oil content by expression of glycerol-3-phosphate acyltransferase genes. Biochem. Soc. Trans. 28, 958-961. doi: 10.1042/bs t0280958
Beganovic for always taking good care of the plants. The initial financial support from SLU chancellor's strategic funding is highly acknowledged. We thank also TC4F (Trees and Crops for the Future) for supporting the research environment, Einar and Inga Nilsson's foundation for its partial financial support to this research and The Royal Physiographic Society of Lund for conference travel supports.

\section{SUPPLEMENTARY MATERIAL}

The Supplementary Material for this article can be found online at: http://journal.frontiersin.org/article/10.3389/fpls.2016.02032/ full\#supplementary-material

FIGURE S1 | Partial PCR results of the transgenic lines of field cress. From left, lanes 1-5 =AtWR/1 gene, lane $6=$ plasmid DNA (+), lane $7=$ wild type (WT) field cress $(-)$, lane $8=$ blank (B), lanes 9-13=AtHb2 gene, lane $14=$ plasmid DNA $(+)$, lane $15=$ WT field cress, lane $16=$ blank $(B)$, lanes $17-20=B v H b 2$ gene, lane $21=$ plasmid DNA (+), lane $22=$ WT field cress $(-)$, lane $23=$ blank (B) and lane $24=$ molecular markers.

Jako, C., Kumar, A., Wei, Y., Zou, J., Barton, D. L., Giblin, E. M., et al. (2001) Seed-specific over-expression of an Arabidopsis cDNA encoding a diacylglycerol acyltransferase enhances seed oil content and seed weight. Plant Physiol. 126, 861-874. doi: 10.1104/pp.126.2.861

Kennedy, E. P. (1961). Biosynthesis of complex lipids. Fed. Proc. 20, 934-940.

Lardizabal, K., Effertz, R., Levering, C., Mai, J., Pedroso, M. C., Jury, T., et al. (2008). Expression of Umbelopsis ramanniana DGAT2A in seed increases oil in soybean. Plant Physiol. 148, 89-96. doi: 10.1104/pp.108.123042

Leiva-Eriksson, N., Pin, P. A., Kraft, T., Dohm, J. C., Minoche, A. E., Himmelbauer, H., et al. (2014). Differential expression patterns of nonsymbiotic hemoglobins in sugar beet (Beta vulgaris ssp. vulgaris). Plant Cell Physiol. 55, 834-844. doi: 10.1093/pcp/pcu027

Lemieux, B., Miquel, M., Somerville, C., and Browse, J. (1990). Mutants of Arabidopsis with alterations in seed lipid fatty acid composition. Theor. Appl. Genet. 80, 234-240. doi: 10.1007/bf00224392

Lenser, T., and Theissen, G. (2013). Conservation of fruit dehiscence pathways between Lepidium campestre and Arabidopsis thaliana sheds light on the regulation of INDEHISCENT. Plant J. 76, 545-556. doi: 10.1111/tpj.12321

Liu, F., Xia, Y., Wu, L., Fu, D., Hayward, A., Luo, J., et al. (2015). Enhanced seed oil content by overexpressing genes related to triacylglyceride synthesis. Gene 557, 163-171. doi: 10.1016/j.gene.2014.12.029

Liu, J., Hua, W., Zhan, G., Wei, F., Wang, X., Liu, G., et al. (2010). Increasing seed mass and oil content in transgenic Arabidopsis by the overexpression of wril-like gene from Brassica napus. Plant Physiol. Biochem. 48, 9-15. doi: 10.1016/j.plaphy.2009.09.007

Merker, A., Eriksson, D., and Bertholdsson, N.-O. (2010). Barley yield increases with undersown Lepidium campestre. Acta Agric. Scand. B Soil Plant Sci. 60, 269-273. doi: 10.1080/09064710902903747

Muhlhausen, A., Lenser, T., Mummenhoff, K., and Theissen, G. (2013). Evidence that an evolutionary transition from dehiscent to indehiscent fruits in Lepidium (Brassicaceae) was caused by a change in the control of valve margin identity genes. Plant J. 73, 824-835. doi: 10.1111/tpj.12079

Nie, X., and Hill, R. D. (1997). Mitochondrial respiration and hemoglobin gene expression in barley aleurone tissue. Plant Physiol. 114, 835-840. doi: 10.1104/ pp.114.3.835

Nilsson, P., Johansson, S. A, and Merker, A. (1998). Variation in seed oil composition of species from the genera Barbarea and Lepidium. Acta Agric. Scand. B Soil Plant Sci. 48, 159-164. doi: 10.1080/09064719809362493

Parent, C., Berger, A., Folzer, H., Dat, J., Crevècoeur, M., Badot, P.-M., et al. (2008). A novel nonsymbiotic hemoglobin from oak: cellular and tissue specificity of gene expression. New Phytol. 177, 142-154. doi: 10.1111/j.1469-8137.2007. 02250.x 
Shen, B., Allen, W. B., Zheng, P., Li, C., Glassman, K., Ranch, J., et al. (2010). Expression of ZmLEC1 and ZmWRI1 Increases Seed Oil Production in Maize. Plant Physiol. 153, 980-987. doi: 10.1104/pp.110. 157537

Spyrakis, F., Bruno, S., Bidon-Chanal, A., Luque, F. J., Abbruzzetti, S., Viappiani, C., et al. (2011). Oxygen binding to Arabidopsis thaliana AHb2 nonsymbiotic hemoglobin: evidence for a role in oxygen transport. IUBMB Life 63, 355-362. doi: $10.1002 /$ iub. 470

Stalberg, K., Ellerstrom, M., Josefsson, L. G., and Rask, L. (1993). Deletion analysis of a $2 S$ seed storage protein promoter of Brassica napus in transgenic tobacco. Plant Mol. Biol. 23, 671-683. doi: 10.1007/BF00021523

Tan, H., Yang, X., Zhang, F., Zheng, X., Qu, C., Mu, J., et al. (2011). Enhanced seed oil production in canola by conditional expression of Brassica napus LEAFY COTYLEDON1 and LEC1-LIKE in developing seeds. Plant Physiol. 156, 1577-1588. doi: 10.1104/pp.111.175000

Trevaskis, B., Watts, R. A., Andersson, C. R., Llewellyn, D. J., Hargrove, M. S., Olson, J. S., et al. (1997). Two hemoglobin genes in Arabidopsis thaliana: the evolutionary origins of?leghemoglobins. Proc. Natl. Acad. Sci. U.S.A. 94, 12230-12234. doi: 10.1073/pnas.94.22.12230

van Erp, H., Kelly, A. A., Menard, G., and Eastmond, P. J. (2014). Multigene engineering of triacylglycerol metabolism boosts seed oil content in Arabidopsis. Plant Physiol. 165, 30-36. doi: 10.1104/pp.114.236430

Vanhercke, T., El Tahchy, A., Shrestha, P., Zhou, X.-R., Singh, S. P., and Petrie, J. R. (2013). Synergistic effect of WRI1 and DGAT1 coexpression on triacylglycerol biosynthesis in plants. FEBS Lett. 587, 364-369. doi: 10.1016/j.febslet.2012. 12.018
Vigeolas, H., Hühn, D., and Geigenberger, P. (2011). Nonsymbiotic Hemoglobin-2 Leads to an elevated energy state and to a combined increase in polyunsaturated fatty acids and total oil content when overexpressed in developing seeds of transgenic Arabidopsis plants. Plant Physiol. 155, 1435-1444. doi: 10.1104/pp .110 .166462

Xu, J., Francis, T., Mietkiewska, E., Giblin, E. M., Barton, D. L., Zhang, Y., et al. (2008). Cloning and characterization of an acyl-CoA-dependent diacylglycerol acyltransferase 1 (DGAT1) gene from Tropaeolum majus, and a study of the functional motifs of the DGAT protein using site-directed mutagenesis to modify enzyme activity and oil content. Plant Biotechnol. J. 6, 799-818. doi: 10.1111/j.1467-7652.2008.00358.x

Zhu, L. H., Li, X. Y., and Welander, M. (2008). Overexpression of the Arabidopsis gai gene in apple significantly reduces plant size. Plant Cell Rep. 27, 289-296. doi: 10.1007/s00299-007-0462-0

Conflict of Interest Statement: The authors declare that the research was conducted in the absence of any commercial or financial relationships that could be construed as a potential conflict of interest.

Copyright (c) 2017 Ivarson, Leiva-Eriksson, Ahlman, Kanagarajan, Bülow and Zhu. This is an open-access article distributed under the terms of the Creative Commons Attribution License (CC BY). The use, distribution or reproduction in other forums is permitted, provided the original author(s) or licensor are credited and that the original publication in this journal is cited, in accordance with accepted academic practice. No use, distribution or reproduction is permitted which does not comply with these terms. 